\title{
OS PROBLEMAS DO RECONHECIMENTO PESSOAL REALIZADO EM SALA DE AUDIÊNCIA E O DIREITO AO SILÊNCIO COMO VIOLÊNCIA NÃO COERCITIVA EM REAÇÃO/CRÍTICA À VIOLÊNCIA ESTATAL
}

\author{
Luize Cristina de Oliveira Alves ${ }^{1}$
}

\begin{abstract}
RESUMO: O objetivo do presente trabalho é analisar os principais problemas relativos a uma das formas de flexibilização do reconhecimento pessoal estabelecido no art. 226 do CPP: o reconhecimento realizado em sala de audiência. Sem qualquer previsão legal, violando o sistema acusatório e flagrantemente indutiva, esta modalidade de reconhecimento constitui verdadeira violência estatal. A evocação ao direito ao silêncio ("nemo tenetur se detegere") aparece, portanto como uma espécie de reação não coercitiva à violência do Estado (paradoxalmente uma violência não violenta). Neste sentido, a seguir, são abordadas as concepções de violência coercitiva estatal e de violência não coercitiva de reação (pacifismo) trabalhadas por Judith Butler em comentário ao trabalho "Para uma crítica da violência" de Walter Benjamin. Em conclusão, é estabelecido o paralelo entre a violência coercitiva estatal que flexibiliza o reconhecimento pessoal e produz provas ilegais e a violência não coercitiva e pacífica do sujeito que recusa se submeter ao reconhecimento.
\end{abstract}

Palavras-chave: Reconhecimento pessoal. Direito ao silêncio. Violência estatal. Violência não coercitiva. Judith Butler. Walter Benjamin.

ABSTRACT: The objective of the present work is to analyze the main problems related to one of the forms of flexibilization of personal recognition established in art. 226 of the CPP: recognition carried out in the courtroom. Without any legal provision, violating the accusatory system and blatantly inductive, this type of recognition constitutes true state violence. The evocation of the right to silence ("nemo tenetur se detegere") appears, therefore, as a kind of non-coercive reaction to state violence (paradoxically, non-violent violence). In this sense, next, the concepts of state coercive violence and non-coercive reaction violence (pacifism) conceived by Judith Butler in a comment to the work "For a critique of violence" by Walter Benjamin are discussed. In conclusion, a parallel is established between state coercive violence that makes personal recognition more flexible and produces illegal evidence and non-coercive and peaceful violence of the subject who refuses to submit to recognition.

Keywords: Personal recognition. Right to silence. State violence. Non-coercive violence. Judith Butler Walter Benjamin.

\footnotetext{
${ }^{1}$ Mestranda pelo Programa de Pós-graduação em Direito da Universidade Federal do Pará (PPGD/UFPA). Membro do Grupo de Pesquisa "Garantismo em Movimento" (CNPq) Assessora do Ministério Público do Estado do Pará (MPPA). Bacharel em Direito pela Universidade Federal do Pará (UFPA). E-mail: alves.luize@gmail.com.
} 


\section{INTRODUÇÃO}

Supostamente em nome da celeridade e da eficiência, surgem, no dia-a-dia do processo penal, modalidades "alternativas" e informais de realização do reconhecimento pessoal. Tais modalidades, para além de representarem quebras das garantias processuais constitucionalmente estabelecidas, estão invariavelmente atingidas pela ilicitude ou ilegitimidade.

O caráter formal do reconhecimento enquanto elemento probatório é reconhecido por Lopes Jr. (p. 488, 2018):

Trata-se de uma prova cuja forma de produção está estritamente definida e,
partindo da premissa de que - em matéria processual penal - forma é garantia,
não há espaço para informalidades judiciais. Infelizmente, prática bastante comum
na praxe forense consiste em fazer "reconhecimentos informais", admitidos em
nome do princípio do livre convencimento motivado.

No trecho, o autor é inclusive categórico ao declinar a possibilidade de reconhecimentos “informais", muito embora reconheça que são práticas judiciais comuns.

Tais modalidades de reconhecimentos alternativos encaixam-se perfeitamente na definição de prova irritual, trazida por Lima (p. 591, 2015): “por sua vez, tem-se como prova irritual a prova típica colhida sem a observância do modelo previsto em lei. (...) trata-se de prova ilegítima, passível de declaração de nulidade”.

No presente trabalho, buscou-se analisar especificamente uma das formas de reconhecimento pessoal realizadas à revelia do art. 226 do CPP o reconhecimento realizado em sala de audiência, apenas com a presença do acusado e no bojo da oitiva do reconhecedor. Assim, são identificados os principais problemas relativos à esta modalidade de produção da prova e apresentar de que forma o direito ao silêncio ("nemo tenetur se detegere”) - na qualidade de uma violência não coercitiva e, portanto, uma reação pacífica à violência estatal - pode ser utilizado como forma de invalidar a prova irritual.

São explorador, portanto, os conceitos de violência estatal e violência não-coercitiva de reação trazidos em "Para uma crítica da violência" por Walter Benjamin e explorados por Judith Butler em "Caminhos divergentes". O principal objetivo é relacionar a flexibilização do reconhecimento pessoal como uma violência produzida pelo estado e o uso do direito ao silêncio por parte do sujeito a ser reconhecido como uma reação pacífica, ou seja, uma reação não coercitiva. 


\section{OS PROBLEMAS DO RECONHECIMENTO PESSOAL DURANTE A OITIVA EM JUÍZO DO RECONHECEDOR}

Uma das modalidades mais comuns no dia a dia dos processos penais é o reconhecimento realizado pela vítima ou pelas testemunhas no momento do depoimento, na própria sala de audiência.

Como sabido, é direito assegurado ao réu de determinado processo penal a permanência na sala de audiências por ocasião da oitiva do ofendido e das testemunhas. Trata-se de desdobramento lógico dos princípios constitucionais do contraditório e da ampla defesa, na medida em que o acusado precisa tomar conhecimento de quais condutas estão lhe sendo imputadas para que exerça sua defesa plena.

$\mathrm{O}$ art. 217 do $\mathrm{CPP}^{2}$ traz inclusive em caráter excepcional a oitiva da vítima ou das testemunhas sem a presença do réu e, para tanto, reveste a hipótese de outras garantias: é obrigatória a presença do defensor constituído e deve constar na ata de audiência os motivos apresentados pelo depoente para não querer depor na presença do réu.

Estando o acusado presente na sala de audiência no momento do depoimento, é pratica recorrente que a acusação ou o próprio juiz perguntem para o depoente se reconhece

o réu ali sentado como autor do crime em apuração. Transforma-se, portanto, o reconhecimento em mera pergunta feita no bojo da oitiva, retirando-lhe todas as garantias e barreiras (bem como a confiabilidade) trazidas pelo art. 226 do CPP.

Para Lopes Jr. (p. 488, 2018), essa informalidade, comumente praticada no dia a dia das varas criminais, é perigosa e viola direitos e garantias fundamentais do acusado. $O$ autor preceitua que:

É uma perigosa informalidade quando um juiz questiona a testemunha ou vítima se "reconhece $(\mathrm{m})$ o(s) réu(s) ali presente(s) como sendo o(s) autor(es) do fato". Essa “simplificação" arbitrária constitui um desprezo à formalidade do ato probatório, atropelando as regras do devido processo e, principalmente, violando direito de não fazer prova contra si mesmo. Por mais que os tribunais brasileiros façam vista grossa para esse abuso, argumentando às vezes em nome do "livre convencimento do julgador”, a prática pode ensejar nulidade.

\footnotetext{
2 Art. 217. Se o juiz verificar que a presença do réu poderá causar humilhação, temor, ou sério constrangimento à testemunha ou ao ofendido, de modo que prejudique a verdade do depoimento, fará a inquirição por videoconferência e, somente na impossibilidade dessa forma, determinará a retirada do réu, prosseguindo na inquirição, com a presença do seu defensor.

Parágrafo único. A adoção de qualquer das medidas previstas no caput deste artigo deverá constar do termo, assim como os motivos que a determinaram.
} 
Um dos maiores problemas desta prática é o fato reduzir a confiabilidade na produção do reconhecimento enquanto elemento probatório, mas manter o "status" de reconhecimento no momento da valoração para o convencimento do magistrado. Dito de outra forma: a mera confirmação por parte da vítima ou de testemunhas de que o réu sentado na sala de audiência, já posto na posição de culpado, foi o autor do crime não é reconhecimento (em razão na inobservância às regras necessárias à produção deste meio de prova); no momento da sentença, porém, os juízes continuam atribuindo o caráter de prova e de reconhecimento a esta mera confirmação, fundamentando a motivação de seu livre convencimento.

Trata-se, em verdade, de continuação de depoimento e não pode possuir a força probatória que um reconhecimento de fato poderia ter desde que realizado de acordo com o procedimento e as garantias legais. Entretanto, no momento subjetivo de formação do livre convencimento do juiz, ainda que a exposição de motivos seja obrigatória, impossível controlar a influência de uma prova produzida de maneira informal.

É o ensinamento de Di Gesu (p. 133, 2010):

Não se pode mais tolerar que réus algemados sejam levados à audiência de instrução e o magistrado convide a vítima a reconhecê-los, pois certamente o farão, tendo em vista ser o imputado o único naquela situação, havendo grave violação das regras processuais.

Neste mesmo sentido, Lopes Jr. (p. 489, 2018):

Logo, não é reconhecimento quando o juiz simplesmente pede para a vítima virar e reconhecer o réu (único presente e algemado...), pois descumpre a forma e é um ato induzido. Contudo, os juízes fazem a título de "livre convencimento", com sério risco de nulidade processual (ilicitude da prova) na medida em que viola o sistema acusatório (gestão da prova nas mãos das partes); quebra a igualdade de tratamento, oportunidades e fulmina a imparcialidade; constitui flagrante nulidade do ato, na medida em que praticado em desconformidade com o modelo legal previsto; e, por fim, nega eficácia ao direito de silencio e de não fazer prova contra si mesmo.

No trecho, o autor traz ainda outros vícios inerentes ao "reconhecimento" realizado no momento da oitiva. Em primeiro lugar: se a pergunta for realizada pelo juiz, representa verdadeira ruptura do sistema acusatório elegido pela Constituição de 88.

Streck (p. 448, 20II) define e aponta as funções deste sistema, indicando sua inegável relação com o princípio democrático fundante da $\mathrm{CF} / 88$ :

De minha parte, entendo que é possível afirmar que o sistema acusatório é o modo pelo qual a aplicação igualitária do direito penal penetra no direito processual-penal. (...) Mais do que isso, é a porta de entrada da democracia. 
É o modo pelo qual se garante que não existe um "dono da prova"; é o modo pelo qual se tem garantia de que o Estado cuida de modo igualitário da aplicação da lei; enfim, é o locus onde o poder persecutório do Estado é exercido de um modo democraticamente limitado e equalizado.

O sistema acusatório caracteriza-se, primordialmente, pela separação de funções entre os sujeitos (partes) processuais, criando uma triangulação na qual o juiz deve estar equidistante das partes e despido de poderes instrutórios (Ferrajoli, 2014). Tal separação fica evidente a partir da análise do art. 129 da CF/88, em especial nos seus incisos I e VIII ${ }^{3}$, que trata das funções institucionais do Ministério Público. Justamente por isso a afirmação trazida por Lopes Jr. (p. 173, 2006): “Quando não existem, devem ser fabricadas, e o Ministério Público é uma parte fabricada. Surge da necessidade do sistema acusatório e garante a imparcialidade do juiz".

Ocorre que tal separação somente no momento inicial do processo, quando da propositura da ação penal (art. I29, I da CF/88), é insuficiente, uma vez que esta não abrange a totalidade do sistema, sendo a iniciativa probatória do juiz franco exemplo de lesão ao sistema acusatório não abarcada (LOPES JR., 2006).

Assim, adentrando na questão da produção de provas, que aqui se faz pertinente, passa-se a discutir a (i)legitimidade do papel instrutório do juiz perante o sistema acusatório. Para Lopes Jr. (p. 182, 2006): “atribuir poderes instrutórios a um juiz - em qualquer fase - é um grave erro, que acarreta a destruição completa do processo penal democrático”. Ainda segundo o autor, quando determinado juiz vai em busca de uma prova processual, ocorre naturalmente uma prevalência da hipótese sobre os fatos, no qual o juiz primeiro toma sua decisão ou forma sua convicção para posteriormente procurar elementos probatórios que corroborem com a hipótese já forjada.

Em resumo, Lopes Jr. explica:

Sempre que se atribuem poderes instrutórios ao juiz, destrói-se a estrutura dialética do processo, o contraditório, funda-se um sistema inquisitório e sepultase de vez qualquer esperança de imparcialidade (enquanto terzietà = alheamento). É um imenso prejuízo gerado pelos diversos pré-juízos que o julgador faz.

\footnotetext{
${ }^{3}$ Art. 129. São funções institucionais do Ministério Público:

I - promover, privativamente, a ação penal pública, na forma da lei;

(...)

VIII - requisitar diligências investigatórias e a instauração de inquérito policial, indicados os fundamentos jurídicos de suas manifestações processuais;
} 
Para Dezem (2008), o entendimento é no sentido de que só é possível que juiz tenha poderes instrutórios em prol da defesa, sendo esta a interpretação que deve ser dada ao art. I56 do $\mathrm{CPP}^{4}$, uma vez que qualquer dúvida em prol da acusação deve conduzir necessariamente à absolvição por aplicação do princípio do in dubio pro reo.

Deste modo, conclui-se que o juiz deve se manter inerte no que tange a produção probatória, configurando verdadeira ruptura do sistema acusatório - elegido constitucionalmente - que o juiz se coloque na posição de acusador e questione a vítima ou a testemunha acerca do "reconhecimento".

Em seguida, outro problema que merece destaque é que, com frequência, não se questiona ao acusado se ele deseja se submeter ao "reconhecimento em audiência". Ora, a Constituição de 88 trouxe, em seu art. $5^{\circ}$, LXIII $^{5}$, como uma das garantias processuais fundamentais o chamado "direito ao silêncio" que deriva de um direito mais amplo que é o direito a não-autoincriminação ou nemo tenetur se detegere (Lopes Jr., 2018).

Para Ferrajoli (p. 560, 2014) o "nemo tenetur se detegere é a primeira máxima do garantismo processual acusatório". Semelhante entendimento possui Amaral (2009) ao afirmar que o direito a não-autoincriminação é fundamental na compatibilização entre o sistema punitivo e o Estado Democrático de Direito.

Em resumo, o direito a não-autoincriminação assegura que o réu ou acusado em um determinado processo penal não pode ser prejudicado, sob nenhuma hipótese, ao se recusar a produzir provas favoráveis à acusação. Dito de outra forma: o sujeito passivo não está obrigado a colaborar com o polo ativo e sua recusa em fazê-lo não altera a presunção de inocência que lhe é garantida ou acarreta em qualquer outro prejuízo processual (Lopes Jr., 2018).

\footnotetext{
${ }^{4}$ Art. 156. A prova da alegação incumbirá a quem a fizer, sendo, porém, facultado ao juiz de ofício: I - ordenar, mesmo antes de iniciada a ação penal, a produção antecipada de provas consideradas urgentes e relevantes, observando a necessidade, adequação e proporcionalidade da medida;

II - determinar, no curso da instrução, ou antes de proferir sentença, a realização de diligências para dirimir dúvida sobre ponto relevante.

${ }^{5}$ Art. $5^{\mathfrak{O}}$ Todos são iguais perante a lei, sem distinção de qualquer natureza, garantindo-se aos brasileiros e aos estrangeiros residentes no País a inviolabilidade do direito à vida, à liberdade, à igualdade, à segurança e à propriedade, nos termos seguintes:

LXIII - o preso será informado de seus direitos, entre os quais o de permanecer calado, sendo-lhe assegurada a assistência da família e de advogado;
} 
Para Lopes Jr. (p. 367, 2018), o princípio do nemo tenetur se detegere constitui a defesa pessoal negativa, assim entendida:

A defesa pessoal negativa, como o próprio nome diz, estrutura-se a partir de uma
recusa, um não fazer. É o direito de o imputado não fazer prova contra si mesmo,
podendo recusar-se a praticar todo e qualquer ato probatório que entenda
prejudicial à sua defesa (direito de calar no interrogatório, recusar-se a participar
de acareações, reconhecimentos, submeter-se a exames periciais etc.).

Ademais, o próprio art. 5ำ, LXIII da Constituição de 88 garante que o acusado deve ser informado acerca do direito a não-autoincriminação. Como o reconhecimento é meio de prova que não exige a participação ativa do acusado, deve lhe ser questionado se deseja ou não participar do ato ou, no mínimo, informado acerca do direito de não se submeter ao reconhecimento. Para Tucci (2004), a ausência de explicitação efetiva deste direito gera a nulidade e, via de consequência, a ilegalidade do ato.

No "reconhecimento" feito em audiência, durante as oitivas, é prática comum que se proceda ao ato sem qualquer questionamento ou fornecimento de informações prévias ao acusado. Assim, além de violar o sistema acusatório, esta informalidade culmina por violar também o princípio do nemo tenetur se detergere.

Por fim, existe o problema relacionado à indução. Como dito, o acusado é o único 1069 com tais características presente na sala de audiências, não raro algemado e já colocado na posição de culpado (as dificuldades de garantir a efetiva presunção de inocência no judiciário brasileiro são notórias). Assim, é natural que a vítima ou as testemunhas, ao serem questionadas sobre o reconhecimento, sejam induzidas a oferecer uma resposta positiva.

Nestes moldes, a memória do reconhecedor não é estimulada. Não se exige que a vítima ou as testemunhas recordem das características físicas do autor do crime. Ao contrário, já lhes é oferecido um modelo que, ainda que involuntariamente, as induz para uma resposta positiva.

A mudança de raciocínio é simples e fica evidente quando traduzida nas seguintes perguntas: "quais as características físicas mais marcantes do autor do fato que me permitem identifica-lo?" e "existe alguma característica física incompatível entre o réu apresentado e minha lembrança do autor do fato?”. Na primeira hipótese o reconhecedor não possui qualquer espécie de indicação ou indução e se vê obrigado a revisitar o maior número de lembranças possíveis que lhe permitam identificar a autoria. No segundo caso, 
o reconhecedor possui uma forte indicação, com efeito indutivo, limitando-se a questionar se existe alguma lembrança incompatível e não mais revista-las em profundidade (Lopes, 20II).

Não à toa o legislador positivou como primeira etapa e garantia do reconhecimento pessoal a indicação das características de quem se pretende reconhecer (art. 226, I do CPP). Percebe-se, portanto, o objetivo de aguçar a memória do reconhecedor, estimulando-a justamente na contramão do processo indutivo provocado pelo "reconhecimento" durante a oitiva.

Percebe-se, portanto, que, diante de todos os problemas apontados, a informalidade na realização do "reconhecimento" pessoal durante a oitiva em juízo da vítima e das testemunhas conduz, invariavelmente à violação de diversas garantias constitucionais dos acusados. Deste modo, é incompatível um processo penal garantista, com respeito à Constituição de 88 e balizado no princípio do devido processo legal com a prática de tal ilegalidade.

\section{VIOLÊNCIA COERCITIVA ESTATAL E VIOLÊNCIA DE REAÇÃO NÂO COERCITIVA DO SUJEITO A SER RECONHECIDO}

No capítulo "Walter Benjamin e a crítica da violência” Butler (2017) parece ter como preocupação principal as violências derivadas dos sistemas normativos, ou seja, as violências produzidas pelo direito e pelo Estado. O primeiro ponto identificado pela autora é a impossibilidade de se tratar o direito ou as leis como formas alternativas à violência (BUTLER, 2017, p. 75). Isto porque tal interpretação conduz à ideia de que na presença da lei, do aparato estatal ou do direito cessaria a violência.

A realidade fática do cotidiano jurídico brasileiro surge na contramão dessa pretensão, demonstrando rotineiramente formas de violências praticadas pelo próprio Estado, supostamente fundadas no Direito ou mesmo a partir do total desrespeito das formas jurídicas. O reconhecimento pessoal realizado em sala de audiência e todos os problemas a ele inerentes e supra identificados exemplificam justamente esta violência do direito pela não aplicação do direito.

Outras questões, entretanto, merecem debate: e uma vez atendido o art. 226 do CPP e realizado o reconhecimento pessoal previsto em lei, este ainda sim não estaria eivado de 
violência? A própria instituição do art. 226 do CPP como meio de prova pelo direito não é uma espécie de violência?

Para Butler (2017, pp. 76-77):

Uma crítica da violência é uma investigação sobre as condições para a violência, mas também um questionamento sobre como a violência se circunscreve de antemão pelas perguntas que fazemos a respeito dela. O que é a violência, então, para que possa ser colocada em questão? Não precisamos tratar essa questão antes de perguntar, como devemos, quais são as formas legítimas e ilegítimas de violência? Entendo que o ensaio de Walter Benjamin fornece uma crítica da violência do direito, o tipo de violência que o Estado exerce por instaurar e manter o status vinculante que o direito impõe sobre quem está a ele sujeito. Em sua crítica, Benjamin oferece pelo menos dois tipos diferentes de explicação. No primeiro exemplo, ele pergunta: como a violência do direito se torna possível? $\mathrm{O}$ que é o direito a ponto de requerer a violência ou, no mínimo, um efeito coercitivo com a finalidade de ter esse caráter vinculante sobre os sujeitos? Mas também: o que é a violência de modo que possa assumir essa forma legal?

Butler (2017) questiona, portanto, acerca da própria natureza da violência estatal para em seguida distinguir dois tipos essenciais desta violência para Walter Benjamin: a violência instauradora do direito e a violência mantenedora do direito. Para o presente trabalho, considerando os objetivos e o objeto da pesquisa, a atenção é voltada para a violência mantenedora do direito que, no que tange ao reconhecimento pessoal, é exercida pelos agentes jurídicos (delegados, juízes e promotores) a partir da flexibilização do art. 226 do CPP.

Em um segundo momento, Butler (2017) apresenta a noção de violência não coercitiva (ou não violenta ou ainda não sangrenta), também trazida por Walter Benjamin. Segundo a autora:

[...]Benjamin abre uma segunda trajetória para seu pensamento: existe outra forma de violência que não seja coercitiva, aliás, uma violência que possa ser invocada e empreendida contra a força coercitiva do direito: Ele prossegue e pergunta: haveria uma violência que não apenas seja empreendida contra a coerção, mas que seja em si não coercitiva e, nesse sentido (ou ainda em outros), fundamentalmente não violenta: Ele se refere a essa violência não coercitiva como 'não sangrenta', e isso parece implicar que ela não é empreendida contra corpos humanos e vidas humanas. Como veremos, no fim não fica claro se ele consegue cumprir essa promessa. Se tivesse conseguido, defenderia uma violência que é destrutiva da coerção, sem derramar sangue algum no processo. Isso constituiria a possibilidade paradoxal de uma violência não violenta, e espero levar em consideração, nas páginas seguintes, essa possibilidade no ensaio de Benjamin (BUTLER, 2017, p. 77).

Nesse contexto, o exercício do direito ao silêncio ("nemo tenetur se detegere") por parte do sujeito a ser reconhecido que irrompe com a flexibilização ilegítima do art. 266 do CPP e culmina com a não realização do reconhecimento pessoal ou mesmo com a nulidade 
da prova produzida parece amoldar-se a esta definição. Trata-se de violência não sangrenta, não exercida sobre corpos e vidas humanas. É, deste modo, uma violência de reação, exercida contra o sistema jurídico e a violência estatal e, por fim, essencialmente não coercitiva e pacífica.

É possível que se questione: se não coercitiva e pacifica porque a violência do direito ao silêncio ainda sim é uma violência? A resposta, apesar de simples, é bastante complexa em conteúdo. $\mathrm{O}$ direito ao silêncio está dentro do direito, previsto no art. $5 \mathrm{da}$ CF88, e como todo o sistema legal, encontra-se impregnado pela já mencionada violência instauradora do direito. Tal forma de violência é justamente aquela que define o que é ou o que não é lei, o que é e o que não é direito (BUTLER, 2017, p. 77).

Em reflexão, a própria expressão "direito ao silêncio", como o "nemo tenetur se detegere" ficou mais conhecido no Direito Brasileiro, traduz esse paradoxo de uma violência não violenta. $\mathrm{O}$ "direito" e toda sua violência instauradora e mantenedora versus o "silêncio" como uma reação pacifista.

Por fim, Butler (2017) adverte que Walter Benjamin não propõe a crítica ou a reação a todos os sistemas normativos, em certo ponto o autor inclusive traz a noção de irredutibilidade da força coercitiva e da violência. Neste sentido, o fim do reconhecimento pessoal enquanto meio de prova no processo penal ou a revogação do art. 226 do CPP não seria, necessariamente uma solução apontada por Walter Benjamin ou por Judith Butler. Pode-se pensar, deste modo, em críticas ao instituto do reconhecimento pessoal que conduzam a uma readequação do dispositivo.

\section{CONCLUSÃO}

O reconhecimento pessoal é espécie de prova cuja forma de realização encontra-se expressa no código de processo penal, mais precisamente no art. 226. Não obstante, no cotidiano jurídico brasileiro são rotineiramente flexibilizadas as regras estabelecidas no referido artigo e realizadas formas alternativas de reconhecimento. Dentre estas formas está o reconhecimento realizado em sala de audiência, no bojo da oitiva do reconhecedor, onde o único sujeito a ser reconhecido é o réu e não raramente conduzida pelo magistrado.

Esta modalidade de reconhecimento, para além da mera ilegalidade por ausência de previsão em nosso ordenamento jurídico (trata-se de prova irritual, portanto), encontra-se 
permeada de outros vícios que acabam por invalidar por completo a prova. Pode-se citar: a quebra do processo penal acusatório com a consequente violação da imparcialidade do juiz, o direito ao silêncio do acusado que por diversas vezes sequer é questionado se deseja ou não se submeter ao reconhecimento pessoal e a nítida indução a que o reconhecedor é submetido a partir da apresentação de apenas um sujeito a ser reconhecido.

$\mathrm{O}$ art. 226 do CPP, segundo as definições de Walter Benjamin e Judith Butler, é por si só uma violência, uma violência instauradora do direito. As constantes flexibilizações a que este é submetido podem ser consideradas como novas formas de violência estatal, desta vez de caráter mantenedor e perpetradas por outros agentes (poder judiciário).

O exercício do direito ao silêncio é, por sua vez, uma violência (porque faz parte do direito, está positivado) não violenta, uma vez que não é exercido contra os corpos e vidas dos sujeitos, mas sim contra o sistema legal. Mais do que isso, é, nas definições de Walter Benjamin e Judith Butler, uma reação pacifista e não sangrenta à violência estatal.

Por fim, ao propor a crítica da violência sem com isso propor o fim de todo e qualquer sistema legal, Walter Benjamin e Judith Butler abrem para a possibilidade de se pensar em uma releitura do art. 226 do CPP, para que a partir da crítica à violência por ele exercida, seja proposta uma readequação que garanta compatibilidade com o ordenamento jurídico e redução da violência estatal-legal.

\section{REFERÊNCIAS}

AMARAL, Thiago Bottino do. Direito ao silêncio na jurisprudência do STF. Rio de Janeiro: Elsevier, 2009.

BUTLER, Judith. Caminhos divergentes: judaicidade e crítica do sionismo. Trad.: Rogério Bettoni. I ed. São Paulo: Boitempo, 2017.

DEZEM, Guilherme Madeira. Da prova penal: tipo processual, provas típicas e atípicas (Atualizado de acordo com as Leis Ir.689/08, 11.690/o8 e 11.719/o8). Campinas: Millennium Editora, 2008.

DI GESU, Cristina. Prova Penal e Falsas Memórias. Rio de Janeiro: Lumen Juris, 2010.

FERRAJOLI, Luigi. Direito e Razão: Teoria do Garantismo Penal. Tradução de Ana Paula Zomer Sica, Fauzi Hassan Choukr, Juarez Tavares e Luiz Flávio Gomes. 4. ed. rev. São Paulo: Editora Revista dos Tribunais LTDA, 2014.

LIMA, Renato Brasileiro de. Manual de processo penal. 3. ed. rev., ampl. e atual. Salvador: Juspodivm, 2015. 
LOPES JR., Aury. Direito Processual Penal. I5. ed. São Paulo: Saraiva Educação, 2018.

LOPES, Mariangela Tomé. O reconhecimento como meio de prova: necessidade de reformulação do direito brasileiro. São Paulo, 20II. Disponível em: www.teses.usp.br/teses/disponiveis/2/2137/tde-10092012-160242/pt-br.php. Acessado em: nov 2018.

STRECK, L. L. O "Novo" Código de Processo Penal e as Ameaças do Velho Inquisitorialismo: Nas So $(\mathrm{m})$ bras da Filosofia da Consciência. In: BONATO, Gilson (Org.). Processo Penal, Constituição e Crítica. Rio de Janeiro: Lumen Juris, 201 .

TUCCI, Rogério Lauria. Direitos e garantias individuais no processo penal brasileiro. 2. ed. rev. e atual. São Paulo: Editora Revista dos Tribunais, 2004. 